Research Article

\title{
Numerical Analysis on the Behavior of Existing Tunnels Subjected to the Undercrossed Shield Tunneling at a Small Proximity
}

\author{
Chunqing Fu $(D)$ and Yuchun Gao \\ Beijing Uni-Construction Group Co., Ltd., Beijing 100101, China \\ Correspondence should be addressed to Chunqing Fu; 59697950@qq.com
}

Received 20 August 2020; Revised 15 November 2020; Accepted 16 December 2020; Published 31 December 2020

Academic Editor: guoqing cai

Copyright (c) 2020 Chunqing Fu and Yuchun Gao. This is an open access article distributed under the Creative Commons Attribution License, which permits unrestricted use, distribution, and reproduction in any medium, provided the original work is properly cited.

\begin{abstract}
Shield excavation in a proximity to existing tunnels inevitably causes deformation and stress change of the adjacent tunnels. Based on the project of new metro line in Beijing where the shield tunnel was constructed under existing tunnel, a modified equivalent stiffness model for the existing tunnel is proposed. Based on this, a three-dimensional finite element is established, and subsequently the proposed modified equivalent stiffness model and the previous model are implemented into the finite element model (FEM), respectively, and then the effectiveness of it is verified through comparison with the field measurements. The results indicate that the modified equivalent stiffness model has excellent agreement with the monitoring value. The impacts of key parameters including undercrossing angle, vertical spacing, and soil parameters on the crown settlement of the existing tunnel are investigated. The maximum settlement of the existing tunnel crown decreases as the undercrossing angle increases. The decease of vertical spacing between the newly constructed tunnel and the existing tunnel leads to an increase of the peak value of crown settlement. As for the soil parameters, friction angle $\varphi$ is the dominant parameter affecting crown settlement of the existing tunnel whereas the cohesion $c$ is least influential. During the process of route selection, it is suggested to keep the vertical spacing between new tunnel and the existing tunnel greater than the external diameter of the new metro tunnel. For the situation of undercrossing an existing tunnel within an extremely small clearance, it is recommended to strengthen the soil as necessary.
\end{abstract}

\section{Introduction}

With the advancement of China's urbanization, the utilization rate of urban underground space continues to increase. Especially after the launch of the national "new infrastructure" strategy, the increase of investment and construction of rail transit inevitably brings the challenges to the underground space. An increasing number of tunnels are constructed or planned near the existing metro lines, and the relative position includes orthogonal, parallel, overcrossing, and undercrossing positions $[1,2]$, resulting in a series of adverse impacts may be observed on the existing tunnel, such as segment deformation, cracking in segment joints [3], and uneven longitudinal settlement of tunnels.
The shield lining composed of segments, bolts, and rubber gaskets is not a continuous homogeneous body [4]. When analyzing the influence of underlying excavation on the existing shield tunnel, a reasonable shield lining model is significant to the accuracy of the calculation result. The current methods of shield tunnel modeling can be generally classified into the following two categories. (1) Segmentjoint model: beam-spring model was proposed by Nishino et al. [5]; shield tunnel as a cylinder could be represented by a simple beam model on an elastic foundation. A new beamdiscontinuous joint model was designed by Zhu [6], and based on the new model, the distribution mode and value of the loading pressure on the lining segments are back-analyzed using the measured data of segment pieces such as axial force and bending moment. Shell-spring model was put 
forward by Zhu et al. [7], with beam elements adopted for segment and segment ring, and spring elements for the joints and bolts of the segment. Shell-spring model can reflect structural performance of the tunnel lining (including the bending stress concentration at the edge of the tube section) in both transverse and longitudinal direction, thereby better evaluating the deformation behavior of the tunnel. The three-dimensional skeleton model [8-10] uses shell elements or solid elements to simulate the tube segments and considers the restraint effects between the tube segments used entities) by spring or contact forces. In addition, this model was used to simulate the tension, compression, shear, and rotation effects of the joints. (2) Equivalent (equivalent stiffness) continuous homogeneous model: equivalent stiffness model proposed by Japanese scholars Shiba et al. [11] reduces the transverse and longitudinal stiffness of the shield tunnel segments and simplifies the tunnel as a continuous homogenized cylinder, so that the effect of the transverse and longitudinal joints in the tube segment can be reflected in the reduction factor. However, the Shiba Yukio model did not consider the influence range of the joint, leading to great deviation between the equivalent stiffness and that of actual situation. Liao [12] modified the longitudinal stiffness of the tunnel and suggested that the influence range of the longitudinal joint of the model is limited, not as large as the entire ring. Liao also discussed the influence range of the circular seam to modify the equivalent continuity model, but the value of which was not given; $\mathrm{Xu}$ [13] discussed the influence coefficient of the annular seam based on two situations where the influence range of the annular seam is within the bolt length and beyond the bolt length; Yu et al. [8] took the influence of the lateral stiffness into consideration and assumed that the tunnel lining presents approximate "elliptical" deformation under the surrounding load and proposed a more effective longitudinal equivalent continuity model for shield tunnels. The equivalent stiffness model, which is simple in calculation and clear in theory, has been widely used in studying the stress and deformation of the existing tunnel. However, the existence of auxiliary structures, such as the track bed, concrete sleeper, and railroad rail, is definitely influential to the stiffness of the whole shield tunnel (operating metro lines).

Based on a project of an existing tunnel undercrossed by shield tunneling of new metro line in Beijing, this paper proposed a modified equivalent stiffness model appropriated for numerical analysis of operating metro lines. Three-dimensional finite element simulation of the existing operating tunnel was performed incorporating with the proposed modified model and comparing with previous models. By analyzing and comparing the predicted crown settlements with monitoring values, the applicability of the proposed modified model is verified. Finally, parametric analysis was carried out based on the proposed modified model, and the recommended selection criteria of undercrossed angles and vertical spacing between new metro tunnel and existing line is given.

\section{Theoretical Model of Longitudinal Equivalent Stiffness}

2.1. Previous Models. At present, the most widely used longitudinal equivalent stiffness model is as follows:

Model 1, the equivalent stiffness model, is proposed by Japanese scholars Shiba et al. [11], and the model reduces the transverse and longitudinal stiffness of shield tunnel segments respectively to obtain a continuous homogeneous cylinder. Moreover, the effect of transverse and longitudinal bolts in the segment is reflected in the transverse and longitudinal stiffness reduction. The model meets the following assumptions: (1) the deformation at each part of the tunnel cross section is proportional to the distance from the neutral axis (as shown in Figure 1) and follows a small deformation hypothesis. (2) The compression is provided by the segment, and the tension is pulled by both segment and bolts when the axis is bent. The model is defined mathematically as follows:

$$
\begin{aligned}
\varphi+\cot \varphi & =\pi\left(\frac{1}{2}+\frac{K_{b} l_{s}}{E_{s} A_{s}}\right), \\
(E I)_{e q} & =\frac{\cos ^{3} \varphi}{\cos \varphi+(\pi / 2+\varphi) \sin \varphi} E_{s} I_{s} .
\end{aligned}
$$

In model 2, Liao [12] modified the longitudinal stiffness of the tunnel based on model 1 and proposed that the influence range of the longitudinal joints of the model was limited instead of the whole ring range. As the influence range of joints is considered in the model, the calculation results have a great agreement with the actual project. The calculation model was as follows:

$$
\begin{aligned}
\varphi+\cot \varphi & =\pi\left(\frac{1}{2}+\frac{K_{b} l_{f}}{E_{s} A_{s}}\right), \\
K_{f} & =\frac{\cos ^{3} \varphi}{\cos \varphi+(\pi / 2+\varphi) \sin \varphi}, \\
(E I)_{e q} & =\frac{K_{f} l_{s}}{K_{f} l_{s}+l_{f}} E_{s} I_{s} .
\end{aligned}
$$

In model 3, Xu [13] specified the influence range of the circular seam within the bolt length and conducted a detailed discussion on the influence coefficient of the circular seam.

When the influence coefficient of the circular seam $\lambda$ is smaller than 1, the effective length of the joint in the influence range of the circular seam is $\lambda l_{\mathrm{b}}$ :

$$
\begin{aligned}
\varphi+\cot \varphi & =\pi\left(\frac{1}{2}+\frac{K_{b} l_{b}}{E_{s} A_{s}}\right), \\
\eta & =\frac{(E I)_{e q}}{E_{s} I_{s}}=\frac{K_{h} \cdot l_{s}}{K_{h} \cdot\left(l_{s}-\lambda l_{b}\right)+\lambda l_{b}} .
\end{aligned}
$$




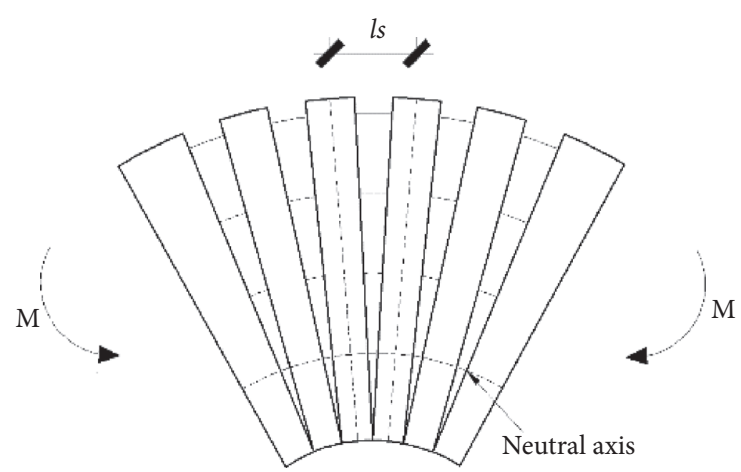

(a)

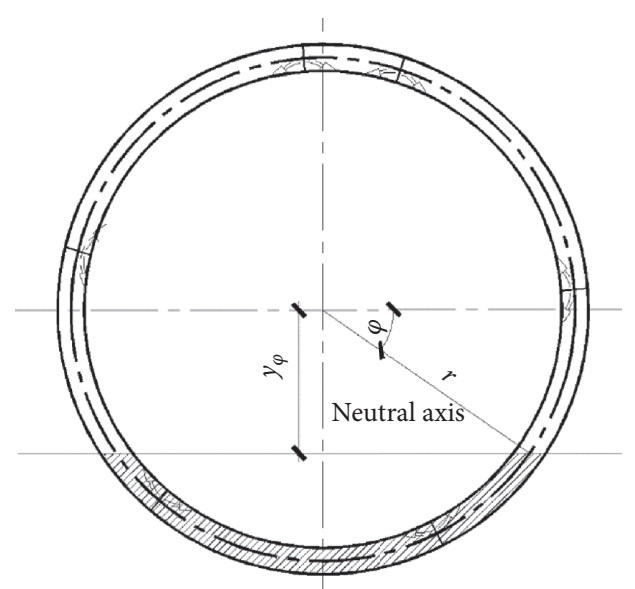

(b)

Figure 1: Schematic diagram of shield lining bending deformation. (a) Deformation of segments joints system subjected to bending moment. (b) Cross section of the deformation of lining.

When the influence coefficient of the circular seam $\lambda$ is greater than or equal to 1 , the effective length of the joint in the influence range of the circumferential seam is $l_{b}$ :

$$
\begin{aligned}
\varphi+\cot \varphi & =\pi\left(\frac{1}{2}+\frac{K_{b} \lambda l_{b}}{E_{s} A_{s}}\right) \\
\eta & =\frac{(E I)_{e q}}{E_{s} I_{s}}=\frac{K_{h} \cdot l_{s}}{K_{h} \cdot\left(l_{s}-\lambda l_{b}\right)+\lambda l_{b}} .
\end{aligned}
$$

In (1) (9), $(E I)_{e q}$ is the equivalent bending stiffness, $\varphi$ is central angle indicating the position of the neutral axis, $E_{s}$ is the elastic modulus of the segment, $I_{s}$ is the moment of inertia of the tunnel cross section, $A_{s}$ is area of cross section of the segments, $E_{b}$ is the elastic modulus of the bolts, $A_{b}$ is the bolt cross-sectional area, $l_{b}$ is the bolt length, $k_{b}$ is the elastic stiffness coefficient of a single bolt, $K_{b}$ is the elastic stiffness coefficient of the longitudinal bolts, $K_{b}=n \bullet k_{b}, n$ is the number of longitudinal bolts, $\eta$ is effective ratio of transverse bending stiffness, $\lambda$ is the influence coefficient of the annular seam, $\lambda l_{b}$ is the length of the influence range of the annular seam, $l_{s}$ is the length of the center line of two segments, and the equivalent coefficient of elastic bending stiffness $K_{h}=K_{f}$.

2.2. Modified Equivalent Stiffness Model. The position of the neutral axis determined in the traditional models does not consider the influence of the track bed, concrete sleeper, and railroad rail, which cannot perfectly represent the mechanical properties of the tunnel. To ensure the safety and stability of the operating line, it is necessary to keep track bed of the tunnel horizontal at all times; therefore, the neural axis is set to be at upper surface of the track bed, as illustrated in Figure 2. Based on this, it is assumed that the magnitude of deformation at any point on the cross section of the tunnel is proportional to the distance from the neutral axis. The compression side only considers the compression of the shield segments, and the tension side is pulled by both concrete and bolts.

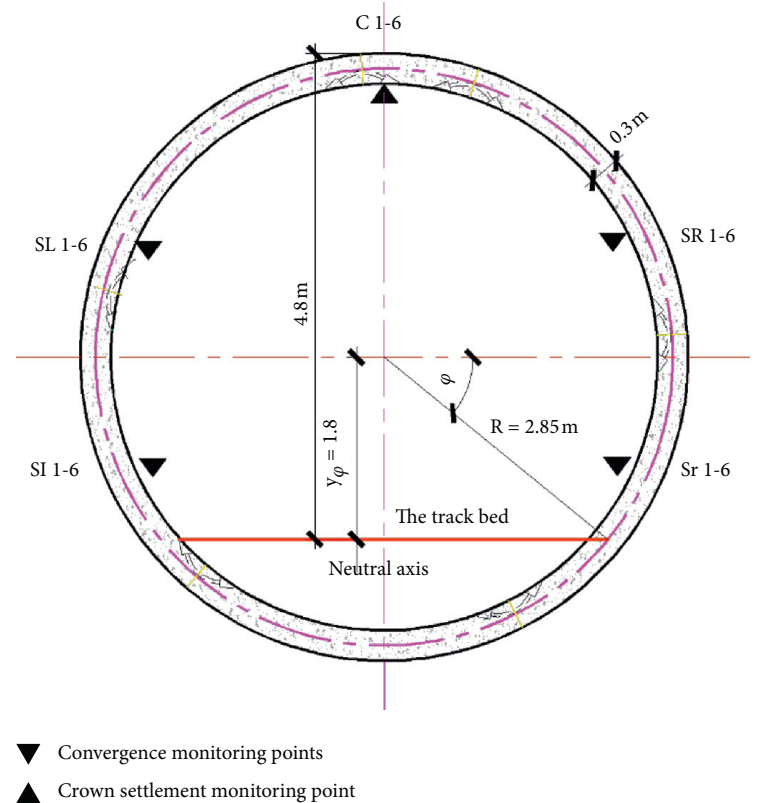

FIGURE 2: Cross section of monitoring points layout on the existing tunnel lining.

Effective ratio of longitudinal bending stiffness $\eta$ can be calculated from the following equations:

$$
\begin{aligned}
& K_{h}=\frac{\cos \varphi^{3}}{\cos \varphi+(\pi / 2+\varphi) \sin \varphi}, \\
& \eta=\frac{(E I)_{e q}}{E_{s} I_{s}}=\frac{K_{h} \cdot l_{s}}{K_{h} \cdot\left(l_{s}-\lambda l\right)+\lambda l_{b}},
\end{aligned}
$$

where $\varphi$ is location of the track bed, as shown in Figure 2 .

\section{Project Overview}

As shown in Figure 3, the newly built shield tunnel of metro line (new metro line) passes under the twin tunnels of 


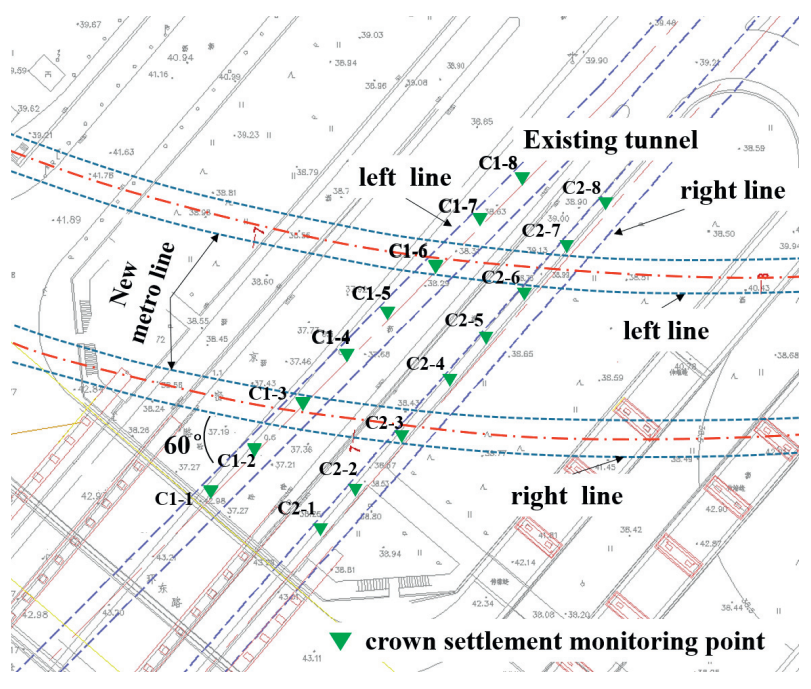

Figure 3: Plan view of undercrossing tunnel.

existing line (existing tunnel) with the skew angle of 60 degrees. To ensure the construction safety to the existing tunnel, monitoring points are usually arranged in the tunnel structure. $\mathrm{C} 1-1 \sim \mathrm{C} 1-8$ are the crown settlement monitoring points of new metro line (left line), C2-1 C2-8 are the crown settlement monitoring points of new metro line (right line). The transversal section of the undercrossed tunnel is plotted in Figure 4. The smallest clearance between the crown of undercrossing tunnel and bottom of existing tunnel is about $4.1 \mathrm{~m}$. The existing tunnels $\left(D_{1}=6 \mathrm{~m}\right)$ are buried mainly in fine sand. The newly built tunnels $\left(D_{2}=6.4 \mathrm{~m}\right)$ are bored in silty clay. The properties of relevant soil stratum are listed in Table 1.

Figure 5 shows the configuration of the lining segments in the newly built tunnels. The standard rings of new metro line and existing line are composed of a key block $(\mathrm{K})$, two adjacent blocks (B1, B2), and three standard blocks (A1, A2, A3). Figure 2 shows the cross section of monitoring points layout on the existing tunnel lining. C 1-6 is the crown settlement monitoring points, whereas SL 1-6, Sl 1-6, SR 1-7, and Sr 1-6 are the convergence monitoring points. The parameters of the linings are listed in Table 2. The lining segments are jointed in staggered arrangement. The joints of the lining rings are connected by 16 connecting bolts (M27), and the parameters used for model calculations are shown in Table 3. C50 concrete is used in the tunnel linings, and the material properties are as follows: P12 for water penetration resistance class (resistance to water pressure of $1.2 \mathrm{MPa}$ ), $3.45 \times 10^{4} \mathrm{MPa}$ for elastic modulus E, and 0.3 for Poisson's ratio $v$.

To retain the stability of working face, the support pressure is set in the range of $0.9 \sim 1.2$ Bar. The diameter of the shield cutter head $\left(D^{\prime}\right.$ or $\left.2 R^{\prime}\right)$ is $6.68 \mathrm{~m}$. The shield segment has an outer diameter of $6.4 \mathrm{~m}$ and a width of $1.2 \mathrm{~m}$. The grouting volume of each ring ranges from $150 \%$ to $200 \%$ of the excavation gap, and the synchronous grouting pressure is controlled between 0.25 and $0.35 \mathrm{MPa}$.

After applying the segment and bolt properties of the project into each model (in section 2), the parameters of longitudinal equivalent stiffness model can be obtained, as shown in Table 4.

\section{Numerical Simulation}

4.1. Numerical Simulation Process. As shown in Figure 6, the three-dimensional finite element model was established under the most unfavorable situation. The dimensions of the model are $300 \mathrm{~m} \times 240 \mathrm{~m} \times 60 \mathrm{~m}$. The boundary conditions are presented as follows: (1) no horizontal displacement along the four vertical mesh boundaries and (2) no vertical or horizontal displacement along the bottom boundary of the mesh. For equivalent (equivalent stiffness) continuous homogeneous model, the lining is simulated as shell elements; the lining rings are connected longitudinally by rigid connections. Model $0(\eta=1.0)$, model $1(\eta=0.11)$, model 2 $(\eta=0.20$, model 3 is close to model 2$)$, and Model 4 $(\eta=0.35)$ are selected for analysis and comparison.

Hardening-soil model is adopted for the ground soil modeling. Poisson's ratio $v_{u r}$ is 0.2 . The dilatancy angle of sand $\Psi$ is $\varphi^{\prime}-30^{\circ}$ (if $\varphi^{\prime}<30^{\circ}, \Psi$ is 0 ), where $\Psi$ can be set to 0 for clay. The power exponent $m$ is related to the stress level ( 0.5 for sand and silt, 1.0 for clay), $E_{u r}^{r e f}=3 E_{50}^{\text {ref }}$ and the reference stress $p_{\text {ref }}$ is $100 \mathrm{kPa}$. The key elastic parameter of loading tangent stiffness $E_{\text {oed }}^{\text {ref }}$ is calculated by the following equation:

$$
E_{\text {oed }}^{r e f}=E_{50}^{r e f}=E_{50}\left(\frac{c \cos \varphi-\sin \varphi \sigma_{3}^{\prime}}{c \cos \varphi+\sin \varphi p^{r e f}}\right)^{-m}
$$

where $E_{50}^{r e f}$ is the secant stiffness of the triaxial experiment and $E_{u r}^{r e f}$ is unloading and reloading stiffness.

Lee et al. [14] addressed that the equivalent ground loss in shield construction is mainly caused by the overexcavation gap between the shield cutter head and the tunnel (including the effect of grouting), the three-dimensional elastoplastic deformation of the soil at the front of the shield, and the construction factors. The ground loss by overexcavation is merely considered in this section. In the simulation, the fixed strain of the mud is used to simulate the influence of the ground loss caused by overexcavation. Considering that shield tunneling adopts zero-settlement tunneling, adding mud effect during tunneling can make shield driving smoothly and control the stratum disturbance to a minimum, so the stratum loss percentage $\eta_{l}$ is usually set to be $0.5 \%$ [15].

4.2. Model Verification. Figure 7 shows crown settlement curves in the longitudinal direction of existing unnel (left line) with different models after completing the left line of new metro line. According to Figure 7, every crown settlement curve is normally distributed with the maximum settlement located directly above the left line of new metro line. The crown settlement acquired by the modified model proposed in this paper (Model 4) is the closest to the monitoring value (C1-1 C1-8). The maximum crown settlement trough is negatively correlated with $\eta$, which increased from $1.11 \mathrm{~mm}$ to $1.65 \mathrm{~mm}$ with the decrease of the equivalent effective ratio $(\eta)$ from 1.0 to 0.11 . 


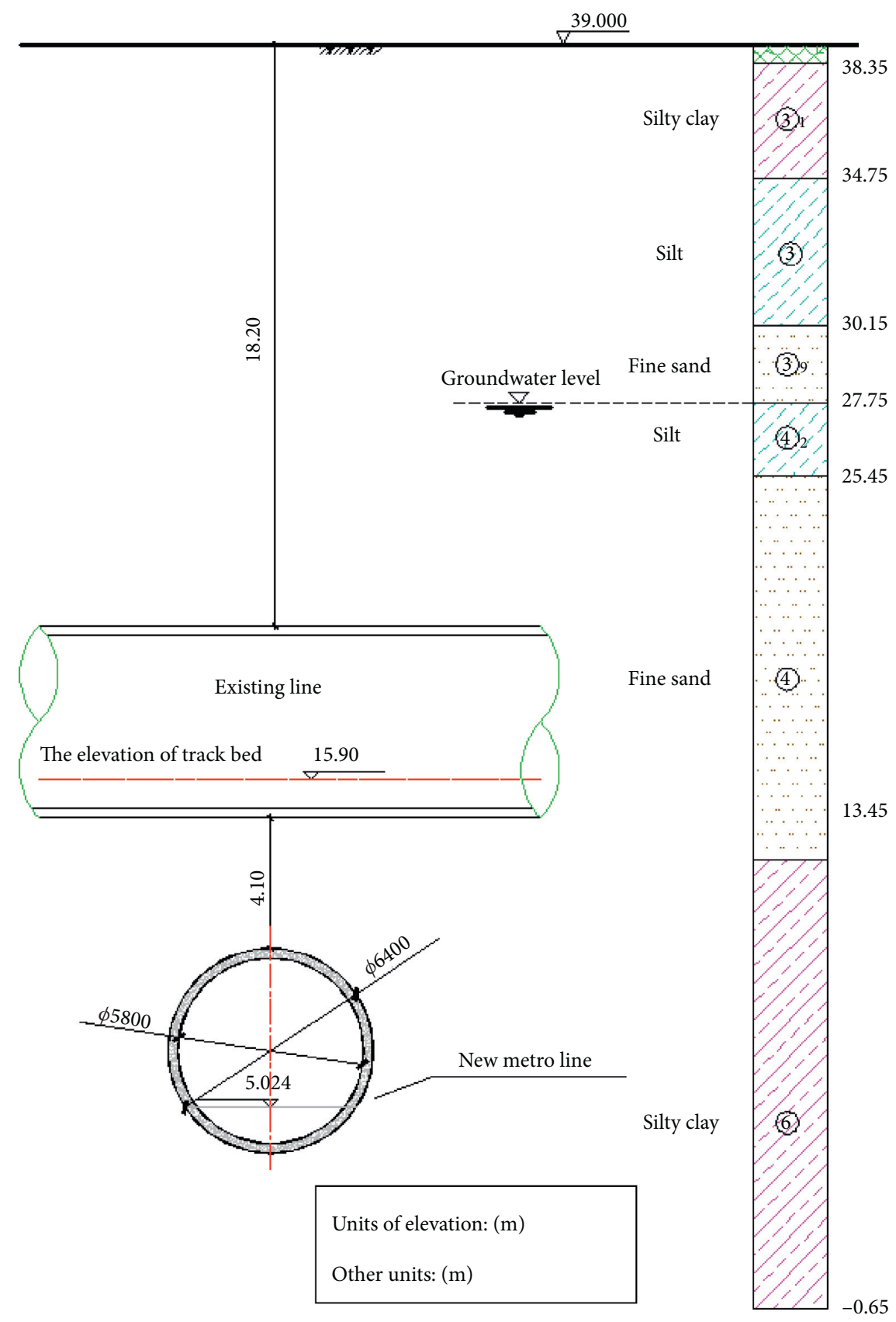

Figure 4: Cross section of undercrossing tunnel.

Figure 8 shows that, after the completion of both lines, each settlement curve is normally distributed with two peaks, respectively, above the centerlines of the left and right undercrossed tunnels. In the longitudinal direction, the settlement trough is " $w$ " shape and the maximum settlements at two peaks are roughly identical. It is easy to find that the settlement of model $4(\eta=0.35)$ is the closest to monitoring values. The estimated result of the crown settlement of the existing tunnel using propose model (model 4) in this paper is in consistency with the field measurements, which indicates that the proposed numerical model can be used to study the optimum shield undercrossing parameters. The crown settlement trough is negatively correlated with $\eta$. When decreasing $\eta$ from 1.0 to 0.11 , the maximum settlement of the tunnel increased by $56.8 \%$, from $1.32 \mathrm{~mm}$ to $2.07 \mathrm{~mm}$. The results show that the equivalent effective ratio $\eta$ has the significant influence on the longitudinal bending deflection of existing tunnel.

The time history curve of the crown maximum settlement of the existing tunnel (left) along with the excavation of the new tunnel is shown in Figure 9. The change in the settlement of the existing tunnel caused by the excavation of new metro line can be roughly divided into three phases: Phase 1, when the tunnel face of new metro line has not passed through the existing tunnel, the tunnel settlement slowly increases with advancing of the excavation; Phase 2, 
TABLE 1: Soil parameters.

\begin{tabular}{|c|c|c|c|c|c|c|c|}
\hline \multirow[t]{2}{*}{ No. } & \multirow[t]{2}{*}{ Soil stratum } & \multirow{2}{*}{$\begin{array}{l}\text { Volumetric weight } \\
\qquad \gamma\left(\mathrm{kN} / \mathrm{m}^{3}\right)\end{array}$} & \multirow{2}{*}{$\begin{array}{c}\text { Compression modulus } \\
\qquad \mathrm{s}_{1-2}(\mathrm{MPa})\end{array}$} & \multicolumn{2}{|c|}{$\begin{array}{c}\text { Consolidated } \\
\text { quick shear test }\end{array}$} & \multirow{2}{*}{$\begin{array}{l}\text { Coefficient of horizontal stress } \\
\qquad K_{0}\end{array}$} & \multirow{2}{*}{$\begin{array}{c}\text { Poisson's ratio } \\
v \\
\end{array}$} \\
\hline & & & & $c_{\mathrm{q}}(\mathrm{kPa})$ & $\varphi_{\mathrm{q}}\left({ }^{\circ}\right)$ & & \\
\hline (3) 1 & Silty clay & 20.2 & 6.45 & 30 & 15 & 0.74 & 0.30 \\
\hline (3) & Silt & 20.2 & 8.71 & 20 & 26 & 0.55 & 0.28 \\
\hline (3) 3 & Fine sand & 20.1 & 4.52 & 0 & 28 & 0.53 & 0.30 \\
\hline (4) 2 & Silt & 20.8 & 12.18 & 18 & 24 & 0.76 & 0.28 \\
\hline (4) & Silty clay & 20.5 & 8.43 & 26 & 14 & 0.36 & 0.27 \\
\hline (6) & Silty clay & 20.3 & 10.35 & 35 & 15 & 0.55 & 0.29 \\
\hline
\end{tabular}

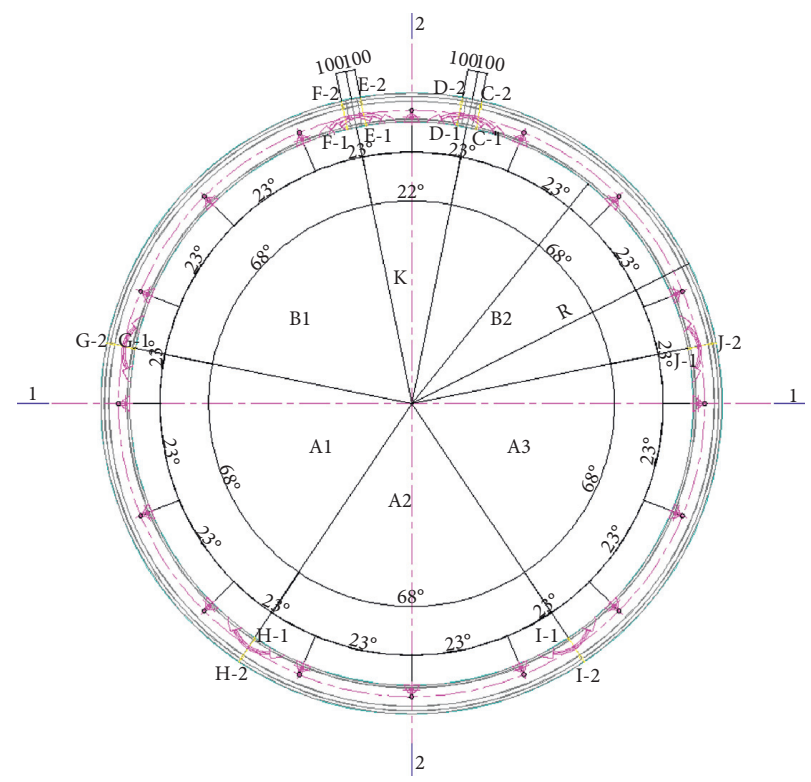

Figure 5: Structure of existing tunnel lining.

Table 2: Parameters of the linings.

\begin{tabular}{lcccc}
\hline \multirow{2}{*}{ Type } & Segment width & External diameter & Internal diameter & Elastic modulus \\
& $l(\mathrm{~m})$ & $D(\mathrm{~m})$ & $6(\mathrm{~m})$ & 5.4 \\
\hline Existing tunnel & 3 & 6.4 & 5.8 & $34.5 \times 10^{3}$ \\
New metro line & 1.2 & 6.4 & $34.5 \times 10^{3}$ \\
\hline
\end{tabular}

TABLE 3: Bolt parameters.

\begin{tabular}{lcccr}
\hline Diameter/mm & $\begin{array}{c}\text { Length } \\
l_{b}(\mathrm{~mm})\end{array}$ & $\begin{array}{c}\text { Young's modulus } \\
E_{b}(\mathrm{MPa})\end{array}$ & $\begin{array}{c}\text { Shear modulus } \\
G_{b}(\mathrm{MPa})\end{array}$ & \multicolumn{2}{c}{$\begin{array}{c}\text { Spring stiffness } \\
K\left(\mathrm{kN} \cdot \mathrm{m}^{-1}\right)\end{array}$} \\
\hline & & & & $K_{\mathrm{x}}$ \\
27 & 600 & $2.06 \times 10^{5}$ & $7.94 \times 10^{4}$ & $K_{\mathrm{y}}$ \\
$K_{\mathrm{z}}$ & & $7.6 \times 10^{4}$ \\
& & & & $7.9 \times 10^{5}$ \\
\hline
\end{tabular}

The rotation of bolt is not considered, so the spring rotation constants $\mathrm{K}_{\theta \mathrm{x}}, \mathrm{K}_{\theta \mathrm{y}}$, and $\mathrm{K}_{\theta \mathrm{z}}$ can be taken as $1 \times 10^{10} \mathrm{kN} \mathrm{m} \mathrm{rad}^{-1}$ [11].

when the tunnel face is within the effective influence region about $100 \mathrm{~m}$, the settlement change rate of the existing tunnel dramatically increases due to the disturbance of the construction of the underpass of the new tunnel; Phase 3, when the tunnel face gradually moves away effective influence region, the settlement of the existing tunnel slowly increases and stabilizes in the end. The changes in settlement of the existing tunnel caused by the excavation of the new metro line (right) are similar to the new metro line (left), but the increase amplitude is not obvious. Comparing the estimated settlements of existing tunnel under different equivalent stiffness, it can be found that the settlement of existing tunnel increases as the reduced $\eta$ decreases. 
TABLE 4: The longitudinal equivalent stiffness models.

\begin{tabular}{lccc}
\hline $\begin{array}{l}\text { Longitudinal equivalent } \\
\text { models }\end{array}$ & $\begin{array}{c}\text { Location of the neutral axis } \varphi \\
(\%)\end{array}$ & $\begin{array}{c}\text { Influence coefficient of circular } \\
\text { seam } \lambda\end{array}$ & $\begin{array}{c}\text { Effective ratio of longitudinal bending } \\
\text { stiffness } \eta\end{array}$ \\
\hline Model 0 & - & - & 1.00 \\
Model 1 [11] & 48.7 & - & 0.11 \\
Model 2 [12] & Change with $\lambda$ & - & $0.2-0.14$ \\
Model 3 [13] & 64.2 & 0.5 & 0.22 \\
Model 4 (modified model) & 39.2 & 0.5 & 0.35 \\
\hline
\end{tabular}

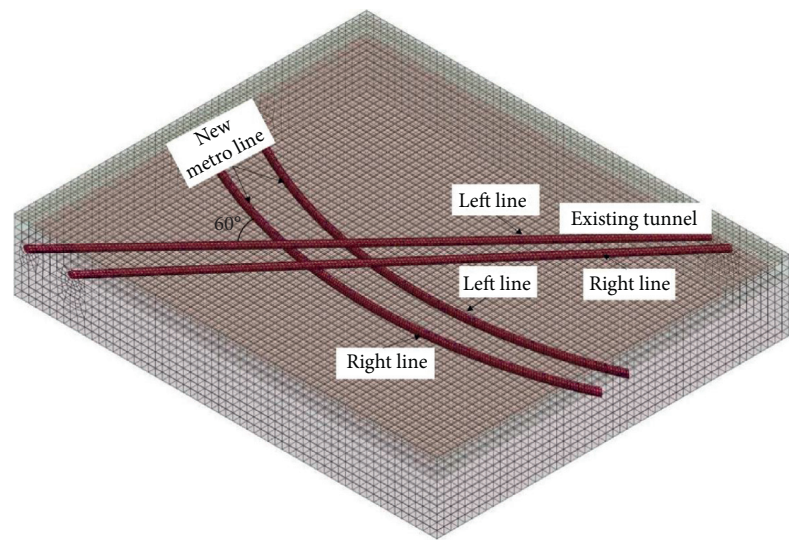

Figure 6: 3-D finite element model.

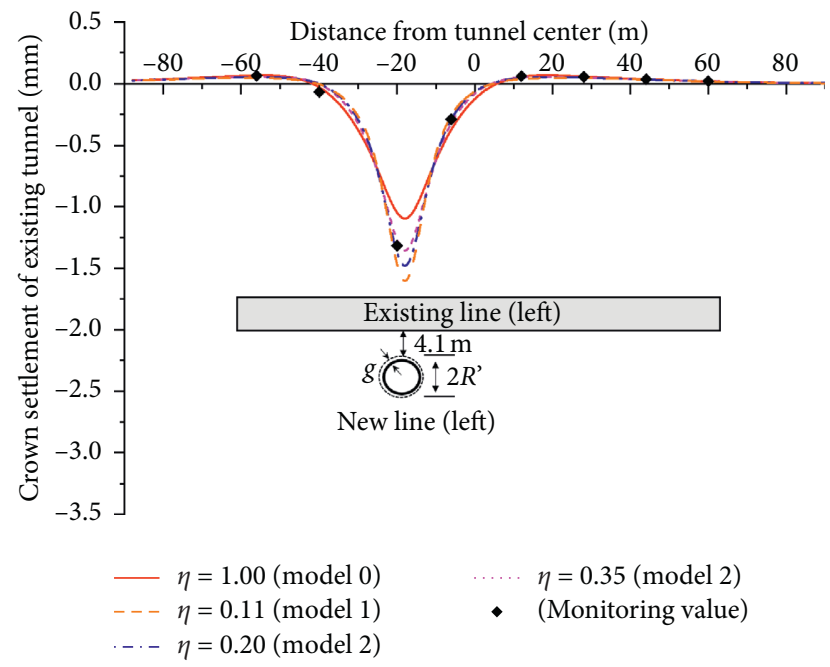

Figure 7: The settlement curves of the existing tunnel after the completion of new metro line (left).

After the completion of the twin line, the convergence ellipse diagrams of the existing tunnel lining using different models are plotted in Figure 10. The red dotted line represents the initial lining ring of the existing shield tunnel, while the other lines represent the fitted convergence ellipses. Since the existing tunnel (left line) is undercrossed from left to right side by the newly built shield tunnel (new metro line), each convergence ellipse tends to elongate

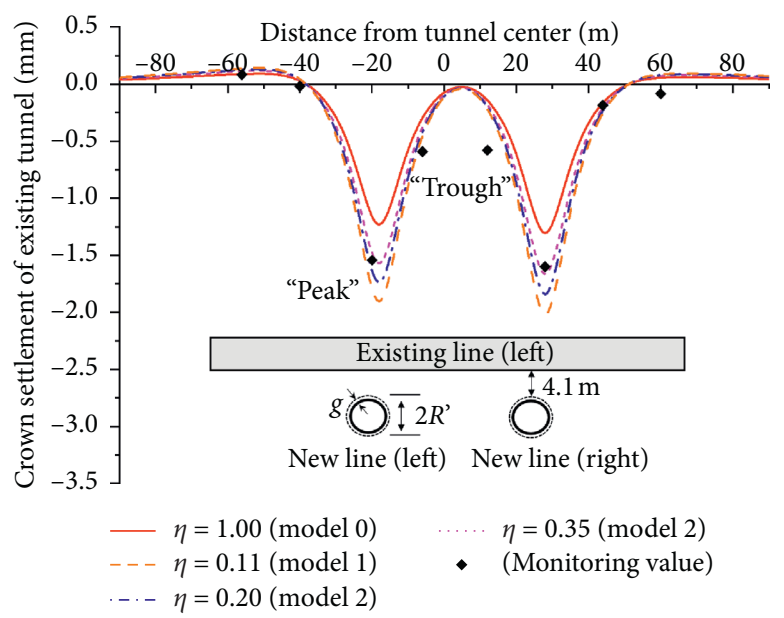

FIGURE 8: The crown settlement curves of the existing tunnel after the completion of new metro line.

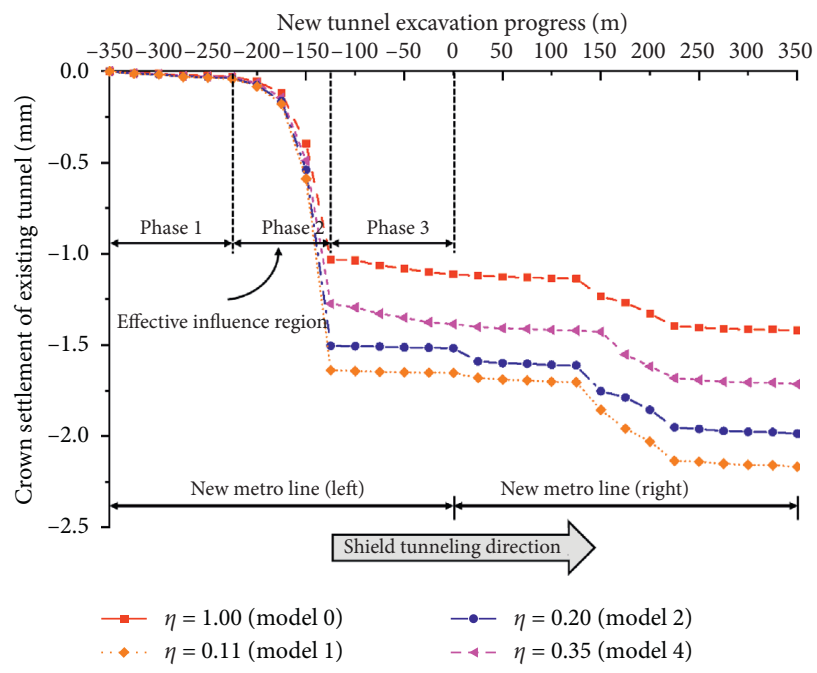

FIgURE 9: The time history curve of the crown maximum settlement of the existing tunnel (left).

towards the lower left corner. With the decrease of $\eta$ in each model, the crown settlement of the convergence ellipse increases from $1.31 \mathrm{~mm}$ to $2.05 \mathrm{~mm}$, and the convergence value increases from $1.45 \mathrm{~mm}$ to $2.12 \mathrm{~mm}$. By comparing the monitoring data with each Model's convergence ellipse of undercrossing section (as Figure 10), it is apparent that the results of model 4 is valid. 


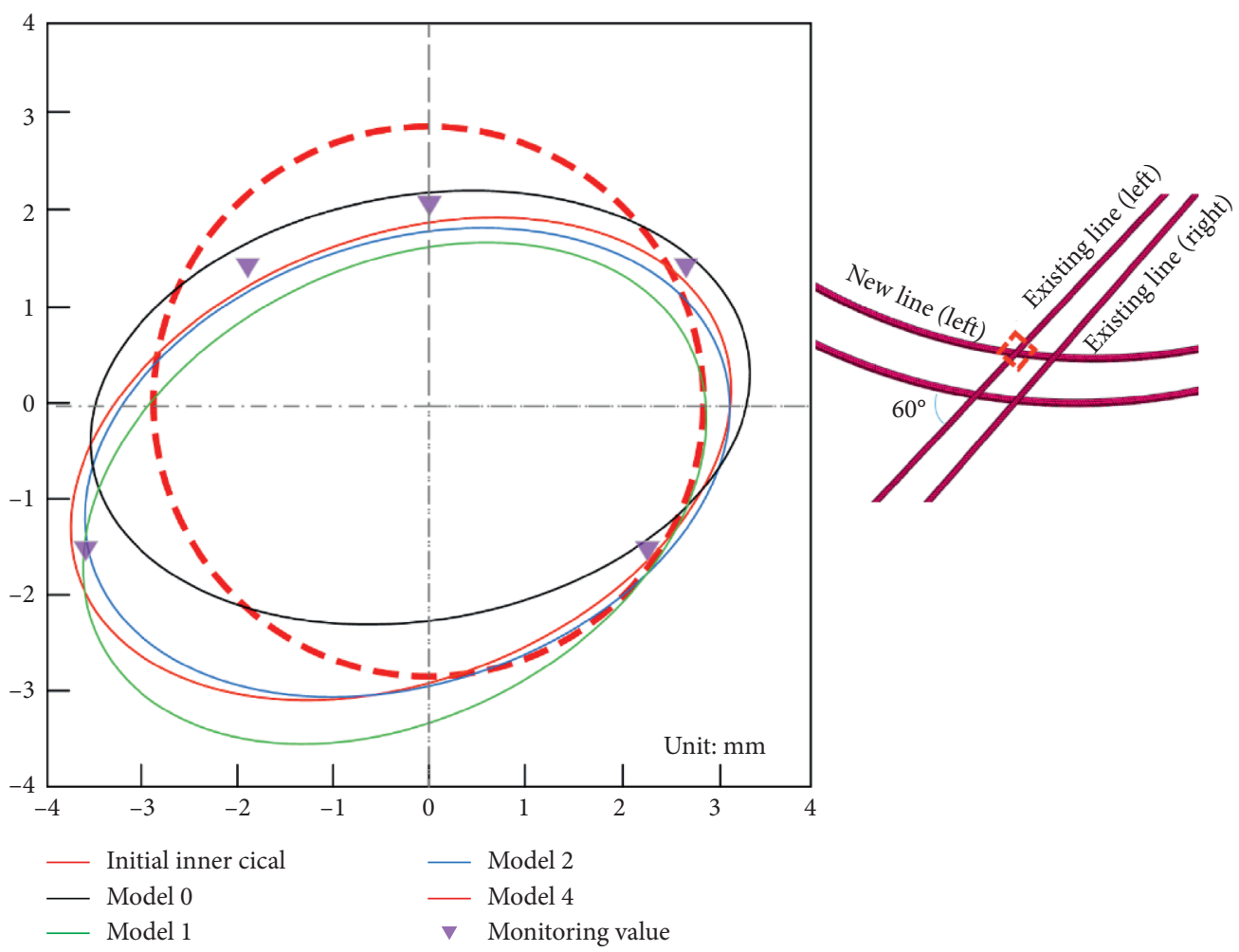

FIgURE 10: Convergence ellipse diagram of undercrossed section.

4.3. Parameters Analysis. The influence of new metro tunnel construction on the existing line depends on many factors, including undercrossed angle, vertical spacing, soil parameters, and construction technology. Analyzing these influencing factors can provide a more objective understanding of the interaction mechanism between the new tunnel and the existing line.

4.4. Undercrossing Angle. Undercrossing angle on the existing shield tunnel is a significant factor considered in the selection of new tunnel lines. In this section, parametric analysis on the selection of different undercrossing angles is carried out based on the modified model (Model 4). As shown in Figure 11, $\varphi_{\mathrm{a}}$ denotes the undercrossing angle $\left(30^{\circ}, 45^{\circ}, 60^{\circ}, 90^{\circ}\right), d_{1}$ is horizontal spacing for twin tunnels of the new metro line, the perpendicular distance of is $40 \mathrm{~m}$, and other parameters are specified in Section 4.1. As shown in Figure 12(a), $\varphi_{\mathrm{a}}$ decreases when $d_{1}$ increases, which leads to the widening of the double peak of " $w$ " shaped settlement trough. As $\varphi_{\text {a }}$ decreases, the area of the cross region of the newly built tunnel and the existing shield tunnel increases, so the width of a single settlement trough is enlarged. According to Figure 12(b), the linear fitting curve of the maximum crown settlement is negatively correlated with $\varphi_{\mathrm{a}}$. When $\varphi_{\mathrm{a}}$ decreases, the peak value of settlement trough increases from $1.61 \mathrm{~mm}$ to $1.83 \mathrm{~mm}$, with a slope of -0.004 . Therefore, in the new line selection process, a reasonably large $\varphi_{\mathrm{a}}$ value is recommended if possible.

4.5. Vertical Spacing. The vertical spacing of newly built shield tunnels under existing tunnel is another critical

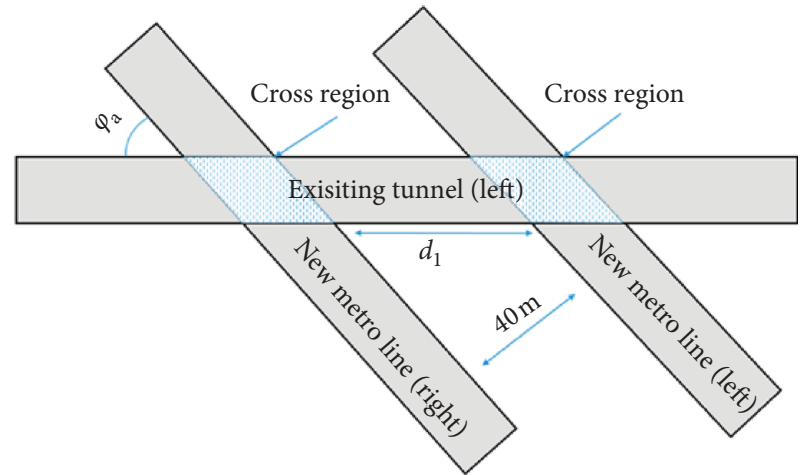

FIgURE 11: Plan view of the new tunnel and the existing tunnel.

influence factor to the settlement of existing tunnel. In this section, the modified model (model 4) is performed with different vertical spacing $d_{\mathrm{v}}$, a constant $\varphi_{\mathrm{a}}$ of $90^{\circ}$, and other parameters specified in Section 4.1. As shown in Figure 13, $d_{\mathrm{v}}$ is set as $0.5 \mathrm{D}_{2}, 1.0 \mathrm{D}_{2}, 1.5 \mathrm{D}_{2}$, and $2.0 \mathrm{D}_{2}\left(\mathrm{D}_{2}\right.$ is the external diameter of new metro tunnel). According to Figure 14(a), the crown settlement curve displays a " $w$ " shape pattern. As $d_{\mathrm{v}}$ decreases, the crown settlement increases. When $d_{\mathrm{v}}<0.66$ $\mathrm{D}_{2}(4.1 \mathrm{~m})$, high rate of increase in the crown settlement can be observed. According to Figure 14(b), the linear fitting curve of the maximum crown settlement trough is negatively correlated with $d_{\mathrm{v}}$. The decrease of $d_{\mathrm{v}}$ leads to an $118.6 \%$ increase in the peak value of crown settlement from $1.18 \mathrm{~mm}$ to $2.58 \mathrm{~mm}$, and the slope is -6.83 . When $d_{\mathrm{v}}>1 \mathrm{D}_{2}$, the peak value of crown settlement increased slowly, and the slope is -0.26 . Therefore, in the planning stage of the route selection 


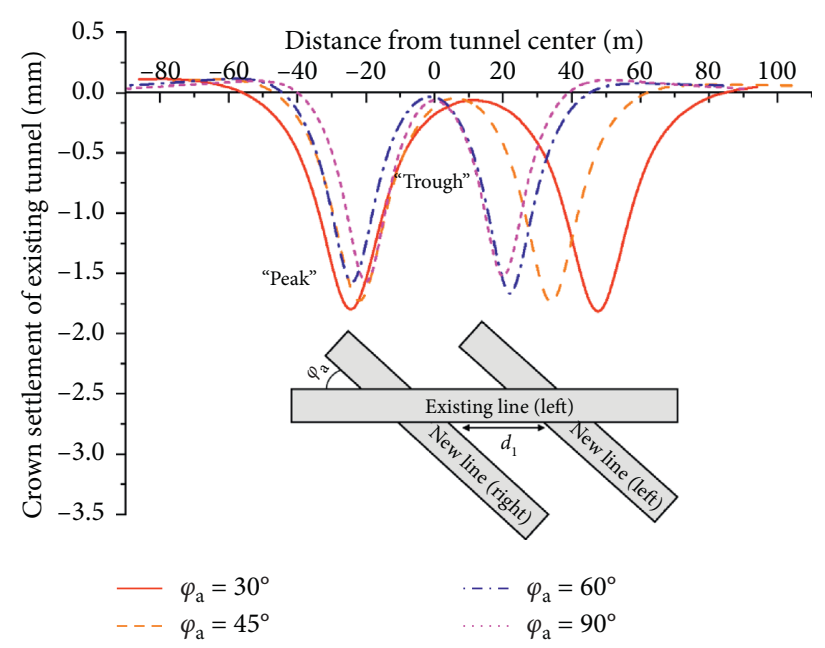

(a)

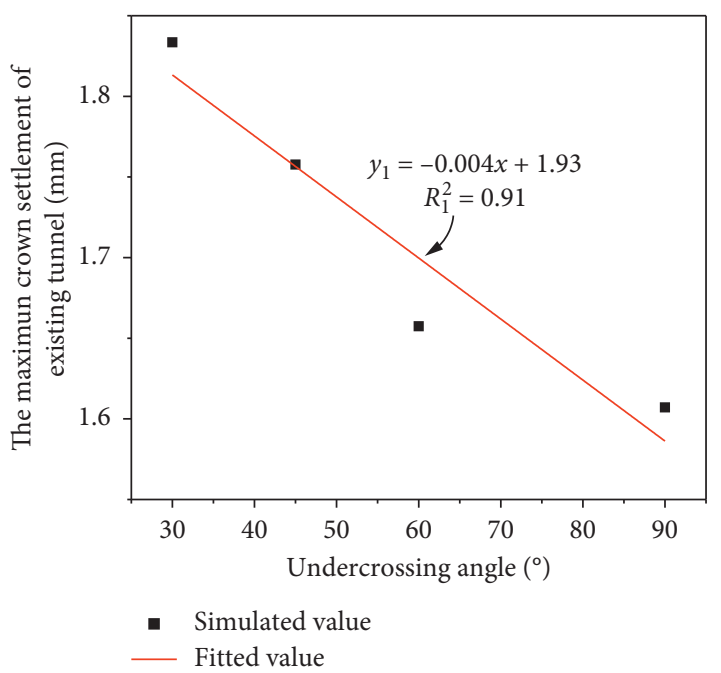

(b)

FiguRE 12: The crown settlement of existing tunnel with the undercrossed angle variation. (a) The settlement curves of the existing tunnel. (b) The linear fitting of the maximum settlement value of the existing tunnel.

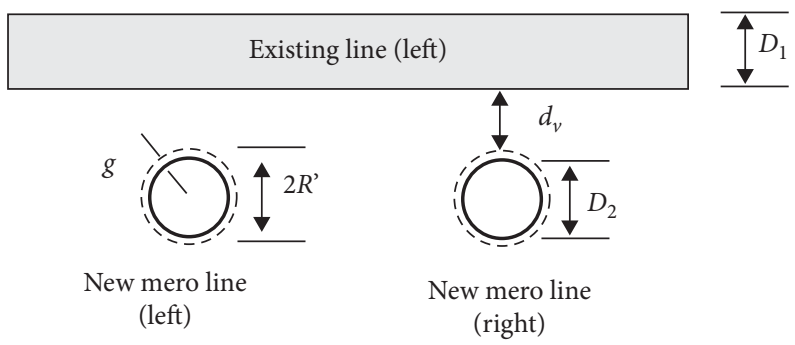

Figure 13: Cross section of the new tunnel and the existing tunnel.

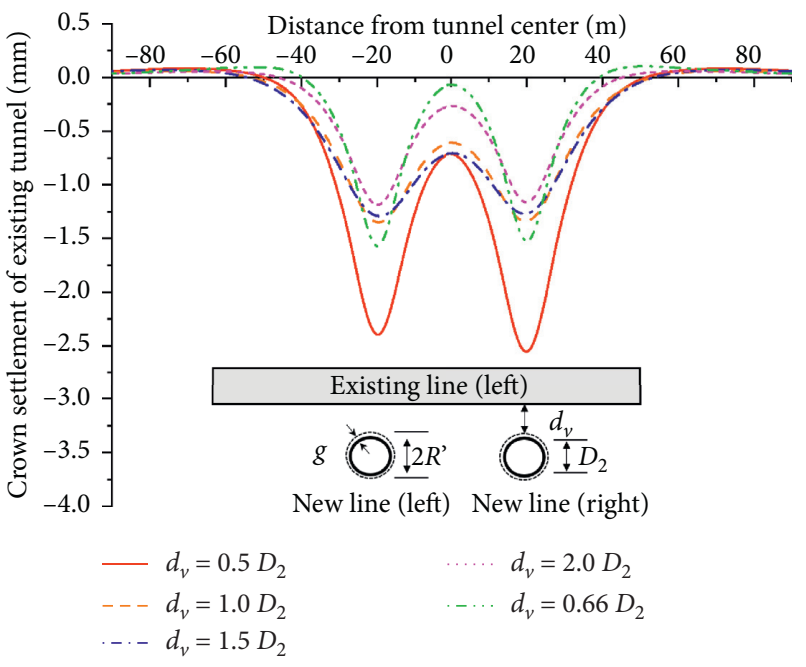

(a)

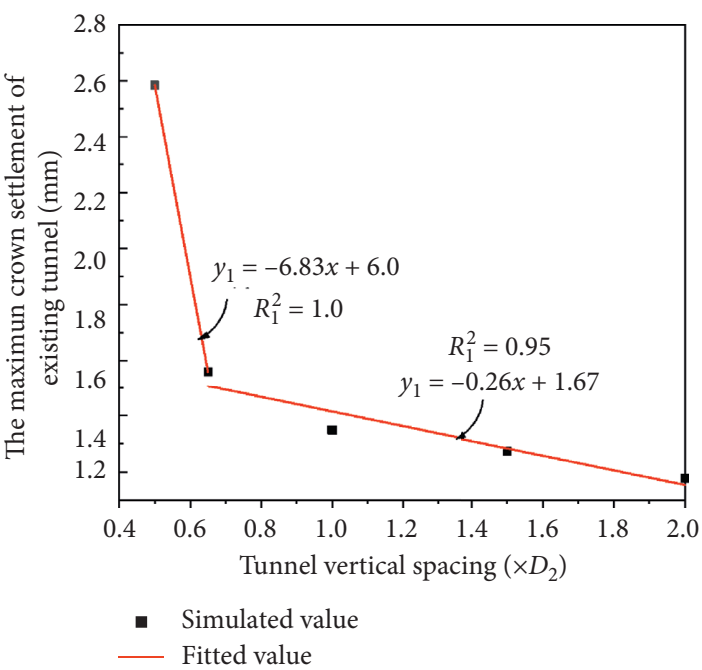

(b)

Figure 14: The crown settlement curves of existing tunnel with the vertical spacing variation. (a) The settlement curves of the existing tunnel. (b) The linear fitting of the maximum settlement value of the existing tunnel. 


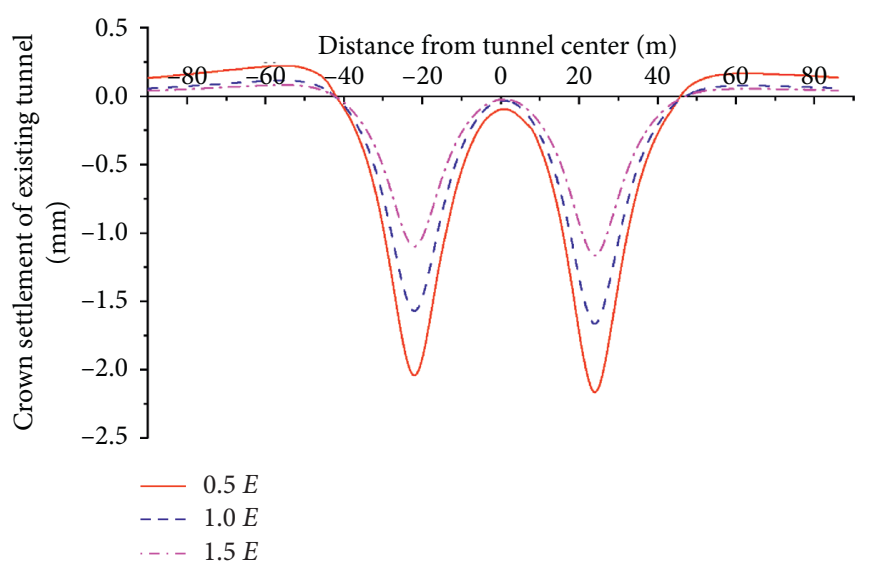

(a)

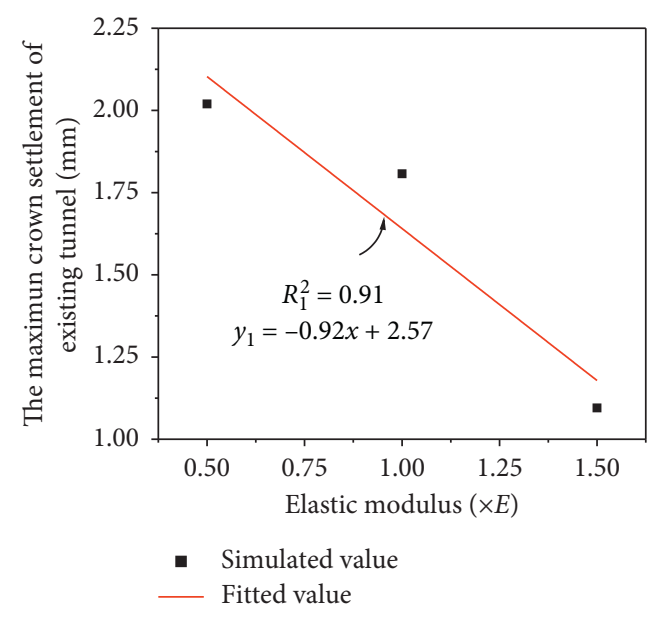

(b)

Figure 15: The influence of soil elastic modulus on the crown settlement of existing tunnel. (a) The settlement curves of the existing tunnel. (b) The linear fitting of the maximum settlement value of the existing tunnel.

of a new line, it is suggested to ensure the vertical spacing $d_{\mathrm{v}}$ is greater than $1 \mathrm{D}_{2}$.

4.6. Soil Parameters. The construction disturbance on the existing tunnel induced by undercrossing tunneling is implemented through the soil, and therefore the soil properties have a decisive effect on the transmission of construction disturbance. Tunneling through weakness stratum involves significant risks and may have disastrous consequences [16]. In this part, a set of various soil parameters (elastic modulus, cohesion, and frictional angle) is applied to the modified model (model 4), with fixed values of $\varphi_{\mathrm{a}}=60^{\circ}$ and $d_{\mathrm{v}}=4.1 \mathrm{~m}$, and other parameters are specified in section 4.1 .

Elastic modulus is one of the main stiffness parameters of soil, and its value directly affects the magnitude of the surrounding ground disturbance caused by shield construction. As shown in Figure 15(a), every crown settlement exhibits a similar "w-shaped" curve. As the elastic modulus of the soil gradually increases, the crown settlement of the existing tunnel caused by the construction decreases moderately. According to Figure 15(b), the linear fitting curve of the maximum crown settlement is negatively correlated with $E$. As the elastic modulus increases from $0.5 E$ to $1.5 E$, the crown settlement of the existing tunnel caused by the construction decreases from $2.22 \mathrm{~mm}$ to $1.20 \mathrm{~m}$ (a decline of $85.0 \%$ ), and the slope is -0.92 .

The shear strength parameters of the soil mainly affect the deformation of the surrounding stratum and the existing tunnel through the friction effect between the tunnel lining and the surrounding soil. The parametric study of cohesion is carried out based on model 4 with soil parameters: $1.0 \mathrm{E}$, $\varphi=30^{\circ}$, and other parameters specified in section 4.1. As shown in Figure 16(a), the influence of cohesion $(c)$ on the crown settlement is similar to that of elastic modulus. Narrow and deep "w-shaped" settlement curves are presented. As $c$ increases, the crown settlement decreases.

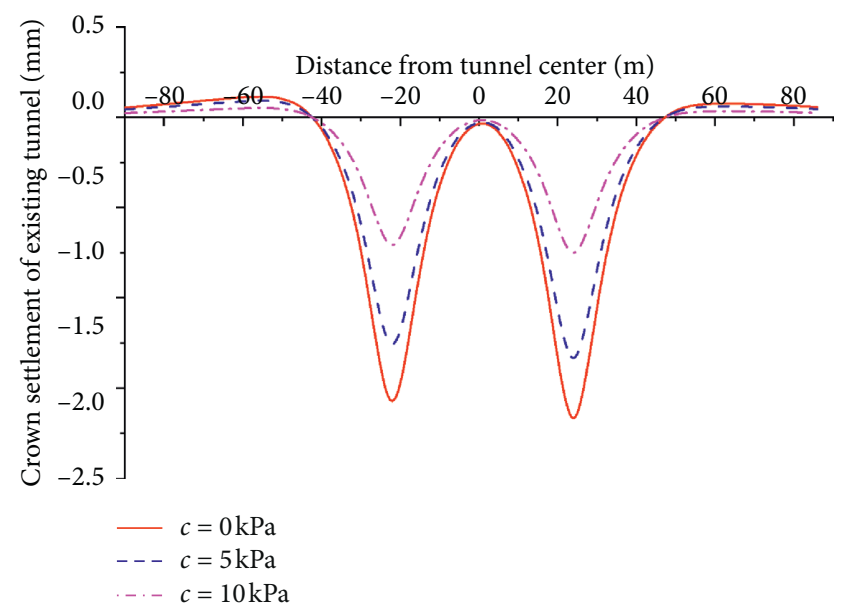

(a)

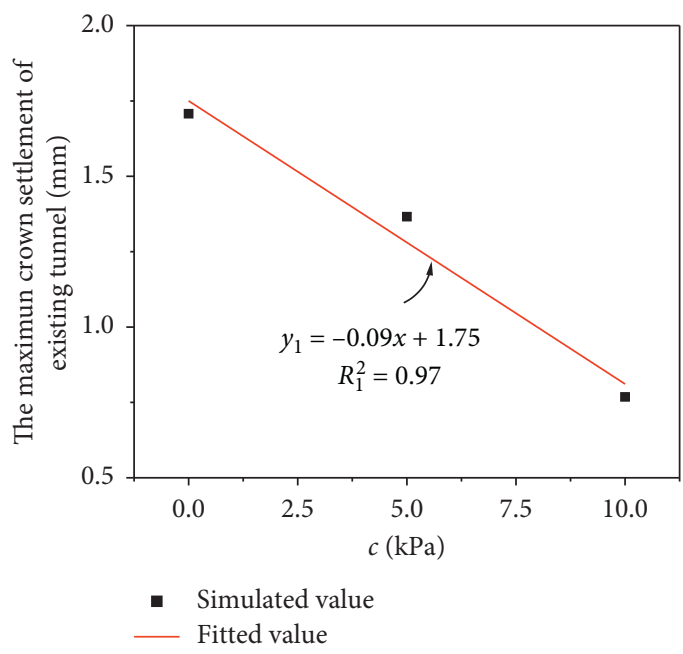

(b)

FIGURE 16: The influence of soil cohesion on the crown settlement of existing tunnel. (a) The settlement curves of the existing tunnel. (b) The linear fitting of the maximum settlement value of the existing tunnel. 


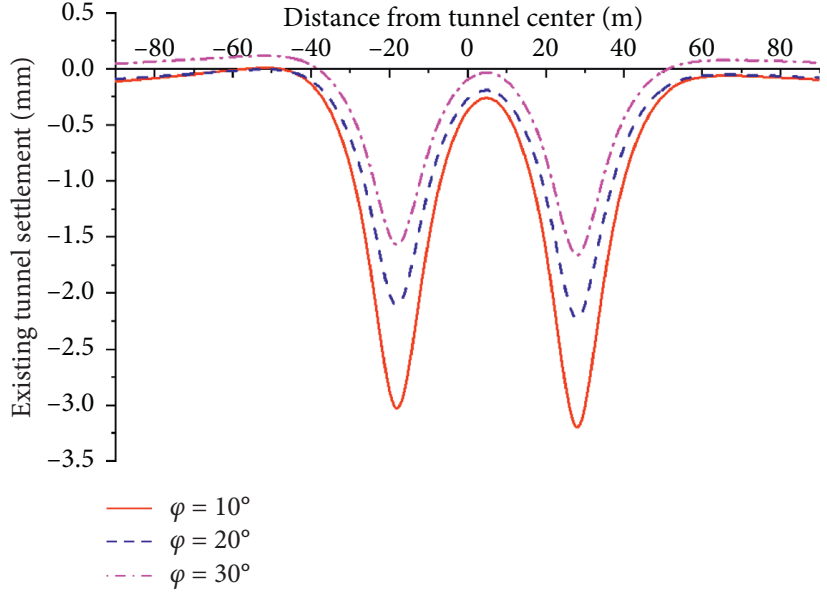

(a)

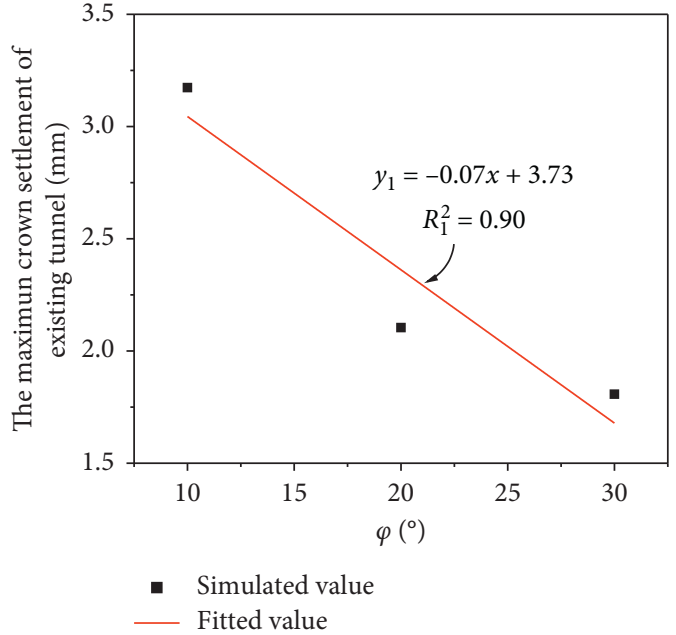

(b)

FIGURE 17: The influence of frictional angel on the inner deformation of existing tunnel. (a) The settlement curves of the existing tunnel. (b) The linear fitting of the maximum settlement value of the existing tunnel.

According to Figure 16(b), the linear fitting curve of the maximum crown settlement is negatively correlated with $c$ : when $c$ increases from $0 \mathrm{kPa}$ to $10 \mathrm{kPa}$, the maximum settlement decreases from $1.71 \mathrm{~mm}$ to $0.77 \mathrm{~mm}$, a decrease of approximately $55.0 \%$.

The parametric analysis of friction angle is based on model 4 with soil parameters of $1.0 E$ and $c=0 \mathrm{kPa}$. As shown in Figure 17(a), the influence of the shear strength parameters friction angle $(\varphi)$ of the soil on the crown settlement is similar to other soil parameters as illustrated in Figures 15 and 16. As $\varphi$ increases, the crown settlement decreases. According to Figure 17(b), the linear fitting curve of the maximum crown settlement is negatively correlated with $\varphi$, and the slope is -0.07 . As the frictional angle $(\varphi)$ increases from $10^{\circ}$ to $30^{\circ}$, the maximum settlement decreases from $3.28 \mathrm{~mm}$ to $1.72 \mathrm{~mm}$, a decrease of about $90.1 \%$. Compared with clay, sand is more sensitive to disturbance, and the width of the settlement trough caused by excavation is larger.

\section{Conclusions}

This paper proposes a modified equivalent stiffness model applicable to crown settlement estimation of the existing tunnel, and its applicability is verified through field measurements based on a project of new metro line undercrossing existing tunnel. The influence of undercrossing excavation on the settlement of the existing tunnel is analyzed. The conclusions are drawn as follows:

(1) The equivalent stiffness models in previous studies did not take the influence of track bed into consideration. In this paper, the track bed is assumed to be the neutral axis in order to get $\eta$ value efficiently and effectively. The applicability of this modified model can be verified through comparative analysis of the crown settlements of existing tunnel.
(2) Through parametric analysis of the undercrossing angle $\left(\varphi_{\mathrm{a}}\right)$ of the newly built shield tunnel on the crown settlement of the existing tunnel, it can be inferred that the area of cross region reduces with the increase of $\varphi_{\mathrm{a}}$, and the decrease of the width of the wave crest as well as the peak of the crown settlement is shown in the crown settlement curve of existing shield tunnel. Therefore, the undercrossing angle should be increased during the route selection process.

(3) Analysis of the crown settlement of the existing shield tunnel shows that as the vertical spacing $\left(d_{\mathrm{v}}\right)$ between the new shield tunnel and the existing tunnel decreases, the peak of crown settlement increases. When the vertical spacing is less than $1.0 \mathrm{D}_{2}$, the peak crown settlement of the existing shield tunnel increases sharply. Therefore, when planning the route of the new shield tunnel, it is suggested to keep the vertical spacing between new shield tunnel and the existing shield tunnel greater than $1.0 \mathrm{D}_{2}$.

(4) Through the discussion of the impact of the soil parameters $(E, c, \varphi)$ affecting crown settlement of the existing tunnel, friction angle $\varphi$ is found to be the dominant parameter whereas the elasticity modulus $E$ and cohesion $c$ is less influential. When undercrossing an existing tunnel within a small clearance, it is recommended to strengthen the soil as necessary.

\section{Data Availability}

The data used to support the findings of this study are included within the article.

\section{Conflicts of Interest}

The authors declare that they have no conflicts of interest. 


\section{Acknowledgments}

This research was supported by the Science Project of Beijing Uni.-Construction Group Co., Ltd. (QTZC-2019-019). This support is gratefully appreciated.

\section{References}

[1] W. Ma, H. Peng, and C. Yang, "Construction parameters control of shield tunnel underneath traversing existing dual shield tunnels," Journal of Southwest Jiaotong University, vol. 53, pp. 119-127, 2016.

[2] S. M. Liao and Y. H. Yang, "Deformation analysis and control of a running subway crossed by upper-and lower-shield in succession," Chinese Journal of Geotechnical Engineering, vol. 34, pp. 812-818, 2012.

[3] J. Han, W. Zhao, P. Jia, Y. Guan, Y. Chen, and B. Jiang, "Risk analysis of the opening of shield-tunnel circumferential joints induced by adjacent deep excavation," Journal of Performance of Constructed Facilities, vol. 32, no. 1, Article ID 4017123, 2018.

[4] H.-N. Wu, S.-L. Shen, S.-M. Liao, and Z.-Y. Yin, "Longitudinal structural modelling of shield tunnels considering shearing dislocation between segmental rings," Tunnelling and Underground Space Technology, vol. 50, pp. 317-323, 2015.

[5] K. Nishino, K. Yoshida, and A. Koizumi, "In-situ tests and consideration on shield tunnel in the longitudinal direction," Doboku Gakkai Ronbunshu, vol. 376, no. 376, pp. 131-140, 1986.

[6] H. Zhu, "Design model for shield lining segments and distribution of load," Chinese Jounal of Geotechnical Engineering, vol. 22, pp. 190-194, 2000.

[7] W. Zhu, Z. R. Huang, and J. J. Liang, "Studies on shell-spring design model for segment of shield tunnels," Chinese Journal of Geotechnical Engineering, vol. 08, pp. 940-947, 2006.

[8] H. Yu, C. Cai, A. Bobet, X. Zhao, and Y. Yuan, "Analytical solution for longitudinal bending stiffness of shield tunnels," Tunnelling and Underground Space Technology, vol. 83, pp. 27-34, 2019.

[9] J. F. Zhang, "Analytical solution and engineering application of the inclined rectangle plate under longitudinal and lateral load," Advanced Materials Research, vol. 168-170, pp. 696-700, 2010.

[10] A. Fatmir, C.-V. Sylvain, L. André, and K. Alwin, "Radiative transfer equation for predicting light propagation in biological media: comparison of a modified finite volume method, the Monte Carlo technique, and an exact analytical solution," Journal of Biomedical Optics, vol. 19, no. 1, Article ID 15002, 2014.

[11] Y. Shiba, K. Kawashima, N. Obinata, and T. Kano, "An evaluation method of longitudinal stiffness of shield tunnel linings for application to seismic response analyses," Doboku Gakkai Ronbunshu, vol. 1988, no. 398, pp. 319-327, 1988.

[12] S. M. Liao, Research on the Effect Longitudinal Shear Transfer on Circular Tunnel Lining, Diss, Norfolk, UK, 2002.

[13] L. Xu, Study on Longitudinal Settlement Behavior of Shield Tunnels in Soft Soil, Diss, Norfolk, UK, 2005.

[14] K. M. Lee, R. K. Rowe, and K. Y. Lo, "Subsidence owing to tunnelling. I. Estimating the gap parameter," Canadian Geotechnical Journal, vol. 29, no. 6, pp. 929-940, 1992.

[15] G. Wei, S. M. Zhang, J. Qi, and N. Yao, "Calculation method of ground deformation induced by shield tunnel construction," Journal of Rock Mechanics and Engineering, vol. S1, pp. 3317-3323, 2006.
[16] P. Shi, D. Zhang, J. Pan, and W. Liu, "Geological investigation and tunnel excavation aspects of the weakness zones of Xiang'an subsea tunnels in China," Rock Mechanics and Rock Engineering, vol. 49, no. 12, pp. 4853-4867, 2016. 